\title{
CARACTERIZAÇÃO GEOMÉTRICA E CINEMÁTICA DA ZONA DE CISALHAMENTO MAJOR GERCINO E SUA IMPORTÂNCIA NA COMPARTIMENTAÇÃO DOS TERRENOS PRÉ-CAMBRIANOS DE SANTA CATARINA
}

\author{
CLÁUdia R. PASSARELLI*, MIGUEL A.S. BASEI* e MÁRIO C. CAMPOS NETO*
}

\begin{abstract}
GEOMETRIC AND KINEMATIC CHARACTERIZATION OF THE MAJOR GERCINO SHEAR ZONE AND ITS IMPORTANCE IN THE COMPARTMENTATION OF SANTA CATARINA PRECAMBRIAN TERRANES. This paper presents the available geometric and kinematic data for the Major Gercino Shear Zone (MGSZ), Santa Catarina State, Southern Brazil. Complex displacement envolving pure shear and simple shear with local dextral and sinistrai movement between the southeastern granite domain and the northwestern mica schists of the Brusque Group, which are separed by the MGSZ is proposed. The quartz c-axis fabrics show the complex evolution of this shear zone where both pure and simple shear mechanisms were very important during the main deformational phase. Based on Fry analysis it was obtained

a S45W-N45E as the main axis of extension direction (X) and a second roughly N-S direction which are in reasonable agreement with the other stretched indicators $(\mathrm{Lm})$. Petrografic studies on mylonite samples allowed the characterization of a low temperature shear zone in which biotite and muscovite are the principal metamorphic minerals developed during shear.
\end{abstract}

Keywords: Shear zone, kinematic indicators, quartz-c axis.

\begin{abstract}
RESUMO Este trabalho apresenta os dados geométricos e cinemáticos para a Zona de Cisalhamento Major Gercino (ZCMG), Santa Catarina, Brasil. Ao longo de sua extensão, este lineamento separa duas áreas geologicamente diferentes que, em Santa Catarina, correspondem aos Domínios Interno (granitóides) e Intermediário (supracrustais) do Cinturão Dom Feliciano. Possui importante movimentação lateral dextral oblíqua, com componentes locais de movimentação sinistrai e apresenta características de deslocamento por cisalhamento simples em presença de faixas com variação de volume. Os milonitos encontram-se metamorfizados na fácies xisto-verde, em presença de biotita e muscovita. Uma componente da deformação por cisalhamento puro foi evidenciada pela análise das petrotramas de eixos-c de quartzo, em rochas miloníticas graníticas. As análises pelo Método de Fry indicam, além da movimentação dextral, orientação do eixo de elongação principal para S45W-N45E e, subordinadamente, para N-S. Uma componente coaxial (cisalhamento puro) também foi evidenciada. O desenvolvimento localizado de estruturas do tipo flor positiva evidencia a presença de domínios transpressivos.
\end{abstract}

Palavras-chave: Zona de cisalhamento, indicadores cinemáticos, eixos-c de quartzo.

INTRODUÇÃ̃ Este trabalho tem como objetivo a apresentação e discussão dos resultados de um estudo estrutural sobre a Zona de Cisalhamento Major Gercino, enfatizando sua caracterização geométrica em superfície e sua caracterização cinemática.

Este lineamento faz parte do importante sistema de cisalhamento com direção NE-SW, que afeta a porção précambriana da região sul-brasileira e uruguaia, recebendo, em Santa Catarina, a denominação de Zona de Cisalhamento Major Gercino (ZCMG), no Rio Grande do Sul de Dorsal do Canguçu e no Uruguai de Sierra Ballena. O segmento estudado situa-se na região centro-este do Estado de Santa Catarina, abrangendo os municípios de Canelinha, Tijipió, Major Gercino e Garcia.

Ao longo de toda sua extensão, a ZCMG separa duas áreas geologicamente diferentes que correspondem, em Santa Catarina, aos domínios interno (granitóides) e intermediário (supracrustais) do Cinturão Dom Feliciano, como definidos por Basei (1985) (Fig. 1).

TRABALHOS ANTERIORES São várias as contribuições ao estudo dos terrenos pré-cambrianos de Santa Catarina, dentre elas, com enfoques mais regionais, pode-se citar as de Kaul (1976), Trainini et al (1978), Silva et al (1985), Basei (1985) e Caldasso et al (1988). Atendo-se ao tema deste artigo, apresenta-se a seguir, a evolução dos

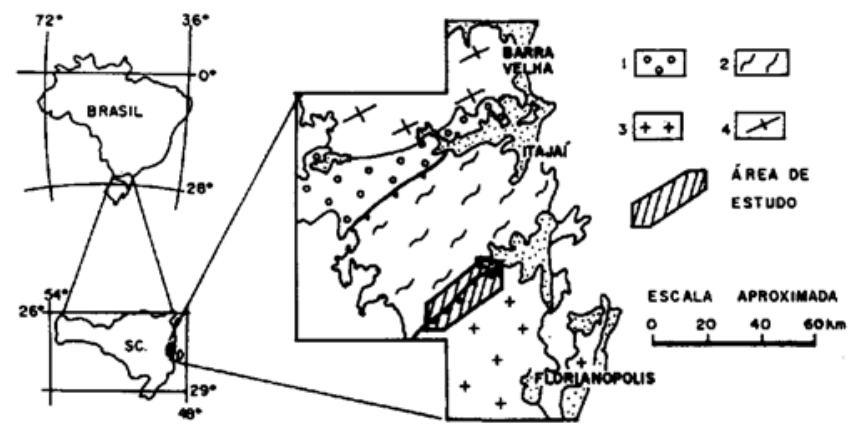

Figura 1 - Principais domínios geotectônicos do Cinturão Dom Feliciano em Santa Catarina (simplificado de Basei et al. 1992). 1. Bacia Molássica de Itajaí (domínio externo); 2. Metassedimentos do Grupo Brusque e granitóides intrusivos (domínio intermediário); 3. Granitóides deformados, gnaisses, migmatitos e granitóides intrusivos (domínio interno); 4. Ortogranulitos (Microplaca Luís Alves) Figure 1 - Main tectonic domains of Dom Feliciano Belt - SC - Brazil (from Basei et al. 1992). 1. Itajaí melasse cover (outer domain); 2. Brusque Group metasediments and intrusive granitoids (intermediate domain); 3. Deformed granitoids, gneisses, migmatites and intrusive granitoids (inner domain); 4. Orthogranulites (Luis Alves Microplate) 
conhecimentos sobre a Zona de Cisalhamento Major Gercino (ZCMG).

A Zona de Cisalhamento Major Gercino foi referida primeiramente por Schulz \& Albuquerque (1969), como Falha Major Gercino, para separar o Grupo Taboleiro do Grupo Brusque.

Trainini et al, (1978) optaram por denominá-la Lineamento Major Gercino, principalmente por sua grande extensão linear e por representar zona de falha com reativações. Este lineamento, segundo os referidos autores, constitui um complexo sistema de falhas com características transcorrentes, ou normais (reativação posterior), que separaria dois compartimentos: o Maciço Mediano Pelotas e o Sistema Dobrado Tijucas (originalmente definido por Hasui et al 1975, como Faixa de Dobramentos Tijucas, onde incluiria os metassedimentos do Grupo Brusque).

Basei (1985) considerou o lineamento de Major Gercino como importante zona de falhas inversas, que separa o domínio interno do domínio intermediário do Cinturão Dom Feliciano, como definido por Fragoso César (1980) nos Estados de Santa-Catarina e Rio Grande do Sul.

Basei \& Teixeira (1987), com base em dados geoquímicoisotópicos do magmatismo no Cinturão Dom Feliciano, consideraram o Lineamento Major Gercino como a principal descontinuidade crustal desses terrenos pré-cambrianos, sugerindo uma zona de sutura de subducção do tipo A.

Foi de Bitencourt et al. (1989) a primeira caracterização deste lineamento como Zona de Cisalhamento Major Gercino (ZCMG), com movimentação lateral dextral. Segundo os autores, a ZCMG apresentaria caráter rúptíl-dúctil.

Basei (1990) apresenta o Lineamento Major GercinoDorsal do Canguçu como sendo estrutura neoproterozóica que separa, ao longo de cerca de $1.200 \mathrm{~km}$, terrenos supracrustais de terrenos granito-migmatíticos. Essa estrutura considerada, como afetando toda crosta e manto litosférico, demarca importantes diferenças isotópicas $(\mathrm{Pb}, \mathrm{Nd}$ e $\mathrm{Sr})$ entre as rochas constituintes dos dois segmentos crustais que separa. $\mathrm{O}$ referido autor conclui que estes segmentos crustais não tiveram evolução conjunta durante toda a sua história geológica, sendo este lineamento uma sutura entre duas placas litosféricas, demarcada por anomalias gravimétricas negativas e lineares (Mantovani et al 1989, 1991 e Hallinan et al 1993).

CARACTERÍSTICAS GERAIS DA ZCMG A ZCMG, na região estudada, caracteriza-se por uma faixa principal a noroeste, com espessura, na superfície, variável entre 1,3 e 3,5 km, onde observam-se desde cataclasitos até ultramilonitos (provavelmente gerados em diferentes episódios), em uma predominância de rochas com texturas protomiloníticas e miloníticas. Limita os metassedimentos do Grupo Brusque, a noroeste (mica-quartzo xistos, filitos e, subordinadamente, quartzitos) de uma zona de granitóides, com largura de até $4 \mathrm{~km}$, onde encontra-se uma série petrográfica quartzo-monzonito porfirítica a monzogranítica, além de sienogranitos com anfibólio (Fig.2).

A sudeste dos granitóides, uma faixa milonítica (Fig. 2), menos espessa (cerca de $500 \mathrm{~m}$ ), encontra-se cilindricamente dobrada, com eixo-B suborizontal orientado para N48E, sugerindo disposição original de fraco mergulho para essa foliação (Fig. 3). As lineações de estiramento observadas apresentam direcão nordeste com caimentos intermediários a baixos. Esse lineamento, a sudeste, deve fazer parte de uma das ramificações da complexa zona de Cisalhamento (Fig. 2).

Falhas com direção aproximadamente N30W, que cortam a ZCMG e provocam rejeitos aparentes, laterais sinistrais, de até $1 \mathrm{~km}$, representam reativações em nível crustal mais superficial.

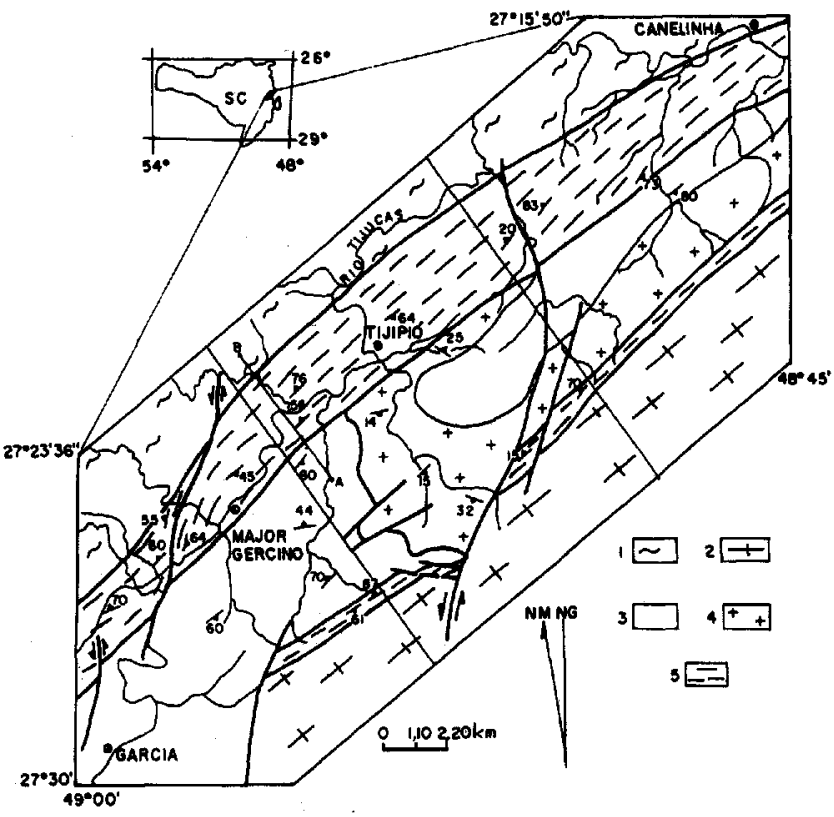

Figura 2 - Esboço geológico da Zona de Cisalhamento Major Gercino entre Garcia e Canelinha (SC). 1. Micaxistos, filitos e quartzitos indiferenciados (Grupo Brusque); 2. Complexo granito-migmatítico; 3. Sienogranitos de granulação grossa, pouco a não-deformados; 4. Quartzomonzonitos a monzogranitos porfiríticos, pouco a nãodeformados; 5. Protomilonitos a milonitos da Zona de Cisalhamento Major Gercino Figure 2 - Outline of the MGSZ in Garcia-Canelinha area (SC). 1. Undifferentiated mica-schist, phyllite and quartzite (Brusque Group); 2. Granite-migmatite complex; 3. Syenogranites, slightly to undeformed; 4. Porphyritic quartz-monzonites to monzogranites, slightly to undeformed; 5. Protomylonites to mylonites of MGSZ

Os dois conjuntos de granitóides, pouco ou não-deformados, aparentemente se relacionam ao desenvolvimento da ZCMG (Fig. 2). Os sienogranitos com anfibólio são rosaavermelhados a cinza-rosados, de textura hipidiomórfica média a grossa. Por vezes apresentam textura inequigranular, com megacristais esparsos de feldspato potássico $(5 \times 2 \mathrm{~cm})$ em matriz de quartzo, feldspato potássico, plagioclásio sódico, anfibólio e biotita. São rochas leucocráticas chegando localmente a hololeucocráticas. $\mathrm{O}$ outro grupo de granitóides, cuja composição é monzogranítica a quartzo-monzonítica, é caracterizado pela cor cinza, textura porfirítica, com megacristais de plagioclásio $(3 \times 2 \mathrm{~cm})$ e de feldspato potássico, em matriz fina-média, composta por quartzo, plagioclásio sódico, feldspato potássico, biotita e, subordinadamente, anfibólio.

Localizadamente, e cortando os granitóides anteriormente descritos, ocorrem alkali-feldspato granites, granitóides ricos em quartzo, riólitos, diques de quartzo-porfiro e diques básicos.

A foliação milonítica apresenta variação sistemática ao longo da faixa principal de milonitos, no trecho estudado da ZCMG. Na porção NE, a foliação possui direção preferencial de $\mathrm{N} 60 \mathrm{E}$ e passa, no domínio central, para N45E e, daí, para N12E na porção S W. Os mergulhos são estatisticamente fortes para sudeste, com exceção do domínio central, onde variam em torno de valores subverticais (Fig. 4).

O comportamento da foliação milonítica, no setor central, pode ser verificado no perfil esquemático (Fig. 5), no qual a estruturação é compatível com uma flor positiva dobrada paralelamente à faixa. 


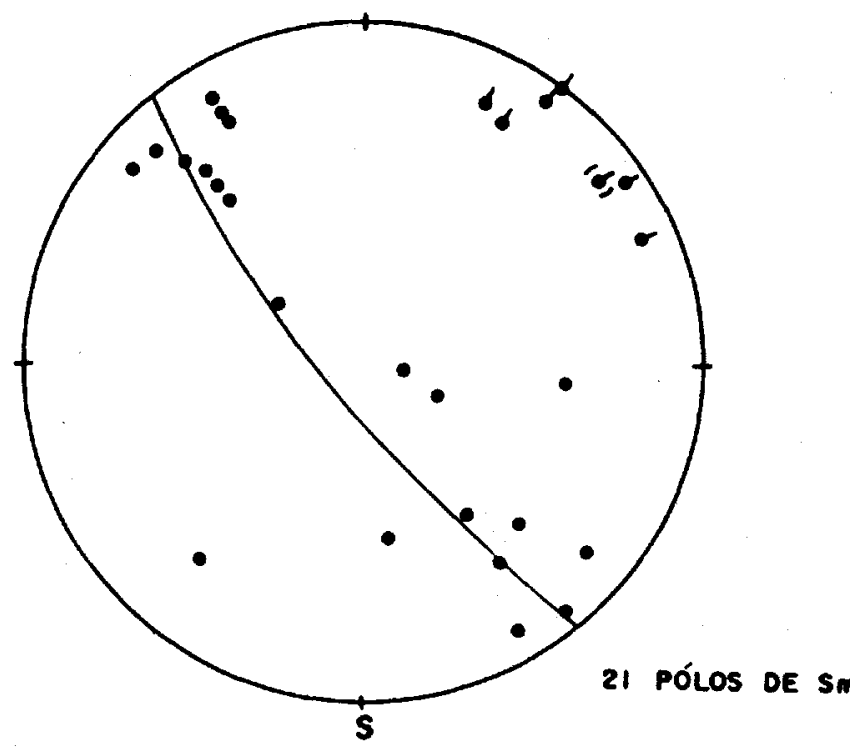

- pólos de follação milonítica

- lineaç̄ó de estiramento muneral

(f) EIXO DE DOBRA CONSTRUIDoO

Figura 3 - Comportamento da foliação milonítica e lineação de estiramento mineral na faixa de milonitos a sudeste da zona de granitóide, apresentando padrão de dispersão possivelmente causado por dobras cilíndricas. Foliação plano axial: N4OE/80NW; eixo de dobra construído: N48E/10

Figure 3 - Attitude of the mylonitic foliation and the stretching lineation in the southeastern mylonites zone deformed by cylindrical folding. Axialplane foliation: N40E/80NW; constructed fold axis: N48E/10.

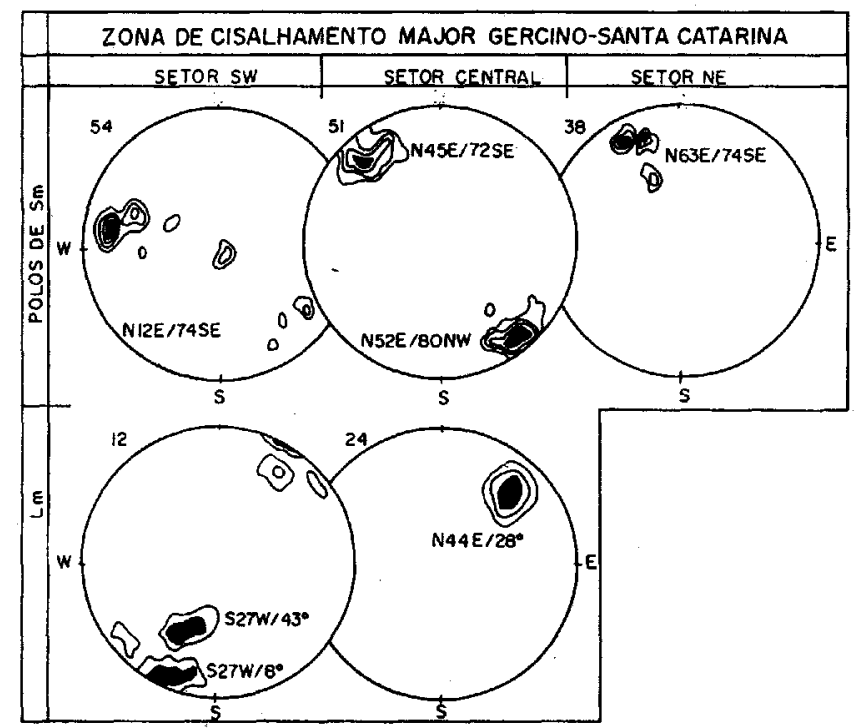

Figura 4 - Comportamento dafoliação milonítica (Sm) e da lineação de estiramento ( $\mathrm{Lm}$ ) ao longo da ZCMG (SC) Figure 4 - Attitude of the mylonitic foliation (Sm) and stretching lineation $(\mathrm{Lm})$ on different sectors of the shear zone

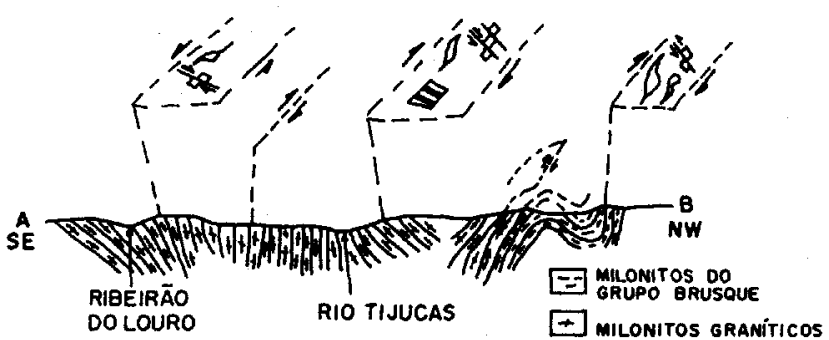

Figura 5 - Perfil A-B esquemático do comportamento da foliação milonítica, porção central da ZCMG

Figure 5 - Cross section of MGSZ (A-B) on central portion

Observa-se também neste perfil (Fig.6), dobras cilíndricas e com eixos-B suborizontais, sugerindo aí fraco mergulho original para a foliação milonítica.

As lineações de estiramento, contidas na foliação milonítica, estão definidas por porfiroclastos de feldspato, por fitas de quartzo e são paralelas a uma lineação mineral com biotita. Orientam-se preferencialmente para N44E (setor central) e S27W (setor sudoeste) e apresentam caimentos fracos, mas que atingem valores entre $28^{\circ}$ (setor central) e $43^{\circ}$ (setor sudoeste).

PETROGRAFIA E METAMORFISMO As rochas miloníticas geradas a partir dos granitóides encontram-se na fácies xisto verde, em presença de biotita. Caracterizam-se

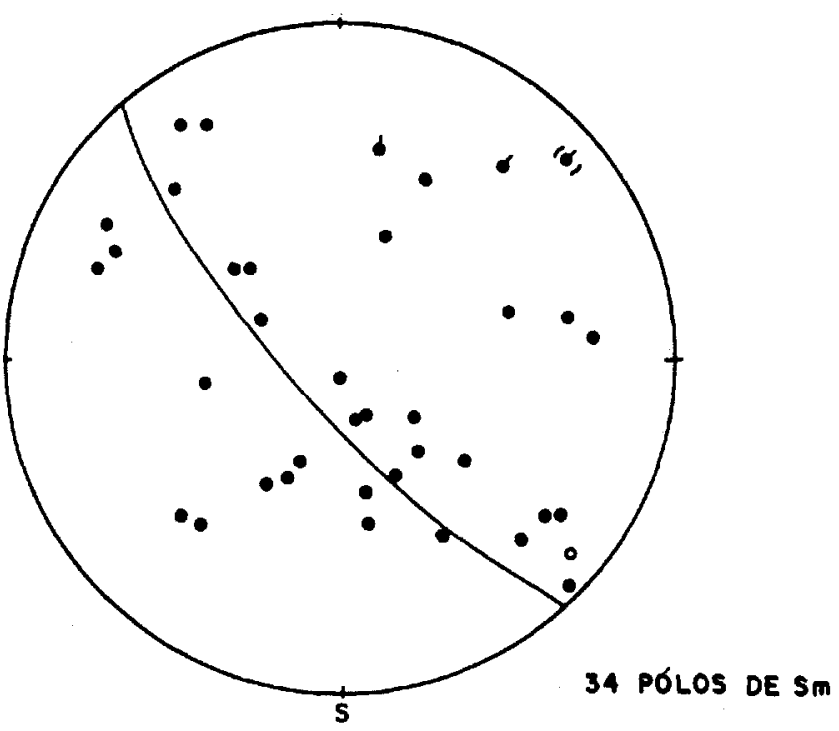

- Pólos de follação mIlonítica

- lineação de estiramento mineral

7) EIXO DE DOBRA CONSTRUÍDO

- Pólo da follação plano axial

Figura 6 - Comportamento da foliaçāo milonítica e lineação de estiramento, no perfil $A-B$, apresentando dobramento cilíndrico. Eixo de dobra construido: $N 52 E / 5$

Figure 6 - Attitude of mylonitic foliation and stretching lineation in A-B profile (central portion) with cylindrical folding. Constructed fold axis: N52E/5 
por biotitas e muscovitas sin-cinemáticas e iso-orientadas, paralelas aos porfíroclastos de feldspatos e quartzo.

Os feldspatos, com textura "mortar" bem caracterizada, encontram-se mais saussuritizados nas porções de maior cominuição. Por vezes, observa-se grãos de plagioclásio e feldspato potássico fraturados, sendo as fraturas geralmente preenchidas por sericita. Não raro, observa-se também deformação nas macias de plagioclásio.

Os grãos de quartzo geralmente apresentam-se estirados, com forte extinção ondulante. São comuns grãos de quartzo em recuperação, apresentando seus contatos serrilhados.

Ocorrem granadas subidioblásticas e poiquiloblásticas, que possuem inclusões orientadas de epídoto e quartzo, definindo foliação interna Si discordante (Fig. 7A), apresentando fraturamento bem marcado (Fig. 7B). Não se observou estiramento ou sombras de pressão e, em.alguns casos, as granadas tardi-cinemáticas deformam a foliação. Por outro lado, tem-se granadas com envoltória micácea (mica cap), indicando posicionamento sin-cinemático.
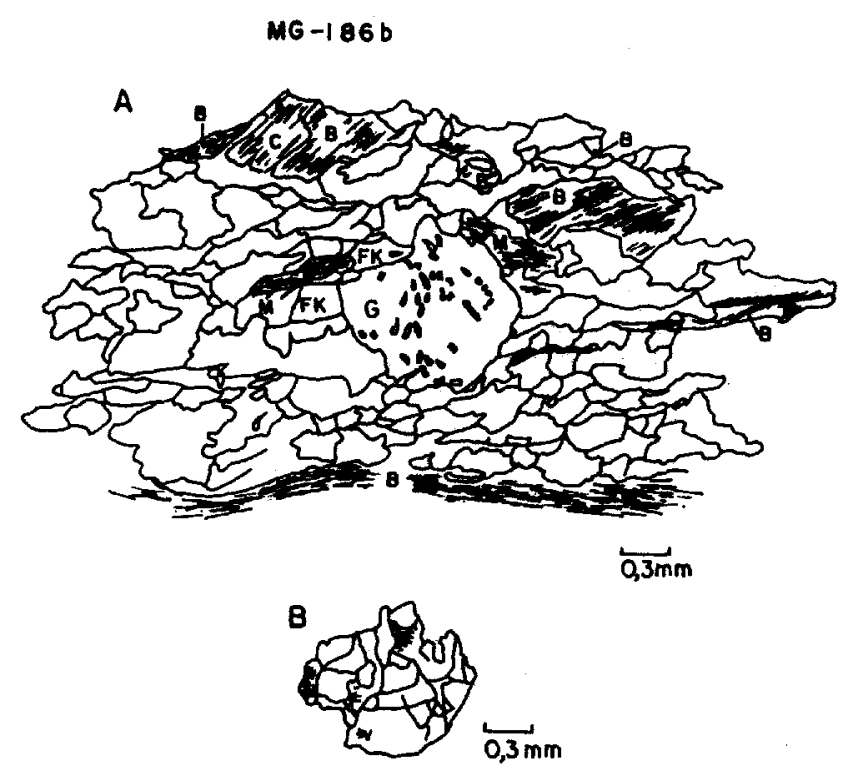

Figura 7 - Feição de escala microscópica de milonitc granítico. A. Seção onde identifica-se porfiroclasto de gra nada com pequena rotação indicada por inclusões de quart zo e epidoto. Os minerais são identificados pelas letras $C$ (granada); B (biotita); $M$ (muscovita); $F K$ (feldspato potás sico); $C$ (clorita), sendo o restante quartzo. B. Detalhe de fraturamento da granada em luz natural

Figure 7 - Sketch of a thin section of granitic mylonite. A. Garnet por phyroclast with rotated epidote and quartz inclusions. Garnet $(G)$, biotite $(B)$ muscovite (M), K-feldspar (FK), chlorite (C) and quartz (open). B. Detai of fractures in the garnet

Nos xistos miloníticos do Grupo Brusque, o metamorflsmo encontra-se no fácies xisto verde, zona da biotita, e gradam localmente à zona da clorita.

Cloritização e epidotização são as principais feições retrometamórficas observadas nos milonitos de granitóides e de metassedimentos.

Os milonitos mostram o predomínio da cominuição dos grãos e da recristalização dinâmica sobre a recristalização estática. O quartzo predomina em grãos estirados, com forte extinção ondulante (contínua ou em domínios), ou em vários grãos com contatos serrilhados. Os grãos recristalizados, com extinção homogênea e com contatos poligonais são subordinados. Nos feldspatos predomina a cominuição e saussuritização, sendo rara a recristalização de microclínios.
Movimentação tardia mais rúptil é sugerida pela presença, incomum, de fraturas em feldspatos e mais raramente em quartzo.

GEOLOGIA ESTRUTURAL Indicadores cinemáticos Os indicadores cinemáticos mesoscópicos observados incluem: sistemas de porfiroclastos (Passchier \& Simpson 1986) do tipo $a_{a}$ elipsoidal (Fig. 8A); porfiroclastos do tipo $\mathrm{a}_{\mathrm{a}}$, com deflexão da foliação milonítica, não apresentando cauda, em protomilonito granítico (Fig. 8B); porfiroclastos do tipo $a_{\mathrm{a}}$ elipsoidal com sombra de pressão, em protomilonito granítico (Fig. 8C); porfiroclastos do tipo $\mathrm{O}_{\mathrm{a}}$ oblongo com sombra de pressão, em protomilonito granítico (Fig. 8D); falhas Anti-Riedel (R'), em milonito e protomilonito graníticos (Figs. 8E e 8F); relação entre as superfícies S e C (conforme definido em Lister \& Snoke 1984) em protomilonito granítico (Fig. 8G); microfraturas de porfiroclastos de feldspatos preenchidos por quartzo, em milonito granítico (Fig. 8H); estruturas dobradas sigmoidais, em milonito granítico (Fig. 81) e grãos de feldspato deslocado em matriz dúctil, em milonito granítico, conforme Simpson \& Schmid (1983) (Fig. 8J).

Os indicadores cinemáticos observados nas seções delgadas restringem-se principalmente a porfiroclastos de feldspatos rotacionados, disposição sigmóide da foliação e presença de mica-fish.

A figura 9 mostra uma cominuição de porfiroclasto de feldspato potássico, apresentando cauda assimétrica composta por fragmentos do porfiroclasto e por quartzo, sericita e biotita. A indicação de movimentação dextral é confirmada pelo padrão sigmóide da foliação milonítica, presente nesta seção delgada.

A foliação S dentro da faixa milonítica (Fig. 4) dispõemse obliquamente à parede da faixa, indicando movimentação dextral. No limite setentrional da faixa, a foliação tende a

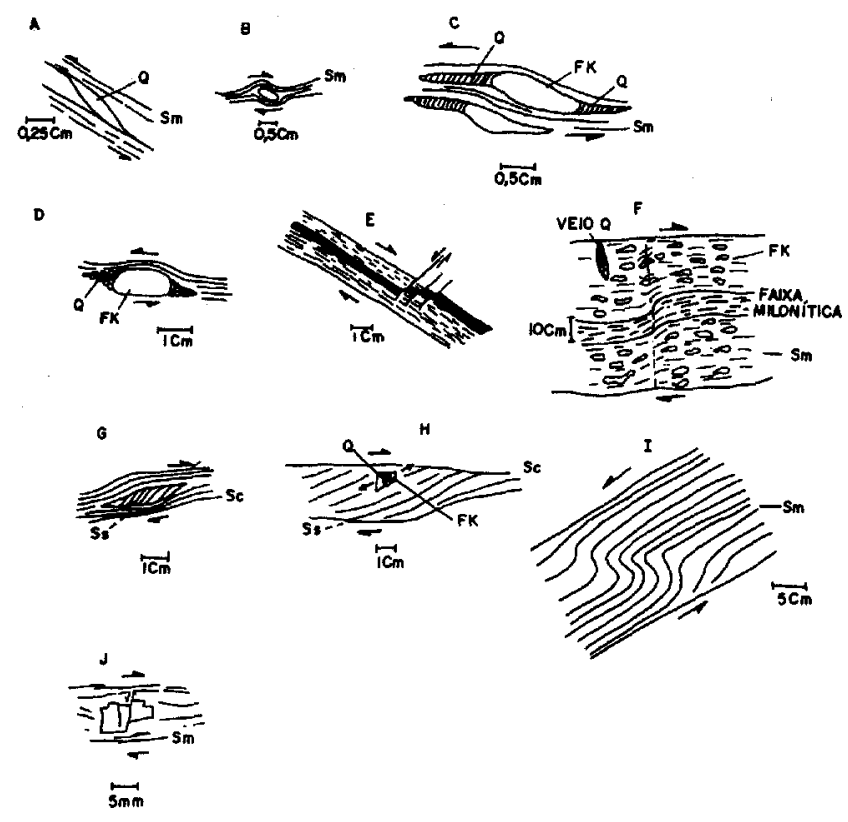

Figura 8 - Principais indicadores cinemáticos observados ao longo da ZCMG, em rochas miloniticas e protomiloníticas. $F K=$ feldspato potásssico, $Q$ - quartzo, $S m=$ foliação milonítica definida principalmente pela orientação de quartzo, feldspato, sericita e biotita Figure 8 - Main kinematic indicators observed in the MGSZ on mylonitic and protomylonitic rocks. $\mathrm{FK}=$ potassic feldspar, $\mathrm{Q}=$ quartz, $\mathrm{Sm}=$ mylonitic foliation defined by quartz, feldspar, sericite and biotite orientation 
se paralelizar às paredes enquanto, no limite meridional, encontra-se truncada bruscamente, sugerindo limite mais rúptil.

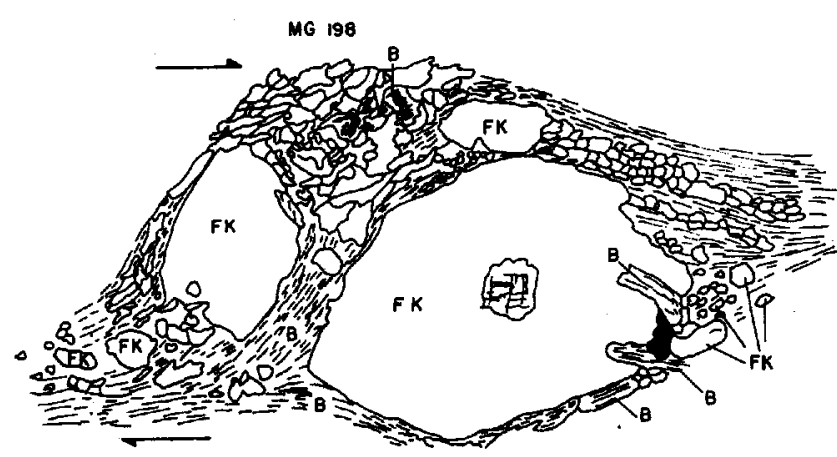

$\widetilde{0,24 m}$

Figura 9 - Cominuição de porfiroclasto de feldspato potássico indicando movimentação dextral. Os minerais são identificados pelas letras FK (feldspato potássico); $B$ (biotita) e o restante quartzo. A porção hachurada é composta predominantemente por biotita, apresentando também sericita e quartzo microgranular Figure 9 - Comminution of K-feldspar porphyroclast indicating dextral sense of displacement. K-feldspar (FK), biotite (B) and quartz (open)

A maioria dos indicadores cinemáticos são de movimentação dextral. Entretanto, indicadores essencialmente sinistrais são freqüentes e podem ocorrer no mesmo afloramento em que se recuperam indicadores dextrais. Existem duas possibilidades de interpretação: 1. tratar-se de zona de cisalhamento reativada em direção oposta; 2. tratar-se de zona de cisalhamento cuja movimentação possui componente coaxial (cisalhamento puro) importante, na qual são encontrados, devido às anisotropias da rocha, indicações de movimento tanto dextral quanto sinistrai.

Sobre a primeira alternativa, não são observados mesoscopicamente ou microscopicamente foliações miloníticas de gerações diferentes, ou seja, não se pode afirmar que houve movimentação inicial dextral e posterior sinistrai ou viceversa. A segunda alternativa parece ter sido confirmada pelos resultados das análises de eixos-c de quartzo e análise da deformação (método de Fry), comentados a seguir.

Eixos-C de quartzo Os padrões de orientação cristalográfica preferencial de quartzo dependem de uma série de fatores, tais como temperatura, taxa de deformação e talvez outras variáveis, como pressão e quantidade de água presente no sistema (Tullis 1977).

Neste trabalho, foram realizadas análises em Platina Universal de 4 eixos, em protomilonitos e milonitos graníticos, seccionados paralelamente à lineação de estiramento. Em cada análise foram medidos 160 pólos de eixos-c de quartzo, sempre movimentando-se a lâmina paralelamente à direção $\mathrm{N}-\mathrm{S}$ da platina.

As amostras analisadas situam-se na faixa milonítica setentrional do mapa geológico (Fig. 2), nos domínios nordeste (A), sudoeste (B) e central (C).

A análise comparativa dos estereogramas, conforme Schmidt \& Casey (1986), indica que a componente rotacional da trajetória da deformação em determinados locais é pequena. Segundo os autores acima citados, estas são características típicas de cisalhamento puro.

Um milonito granítico do domínio nordeste (amostra MG-186b, Fig. 2) apresenta simetria monoclínica, controlada pela distribuição dos máximos dos pólos de eixos-c de quartzo ao longo de dois círculos mínimos em torno do eixo$\mathrm{Z}$ e simétricos à foliação milonítica (Fig. 10A). Este caso é típico de deformação de baixa temperatura ou de altas taxas de deformação (Tullis 1977) em campo de achatamento de deformação coaxial ou de compressão axial (Dell'Ângelo \& Tullis 1989, Schmidt \& Casey 1986, Tommasi et al 1994).

Nesta amostra, apesar das curvas de contorno dos pólos de eixo-c tenderem a uma simetria à foliação milonítica, suas densidades não são simétricas, o que pode indicar deformação não-coaxial (no caso um cisalhamento simples dextral) superposta a uma deformação coaxial (conforme simulações citadas em Lee et al. 1987). Esta sugestão é coerente com os grãos de quartzo medidos, que encontramse fortemente estirados e com extinção ondulante.

Um milonito granítico do domínio central (amostra MG198, Fig. 2) apresenta o padrão acima descrito já descaracterizado, pois seus contornos não se apresentam simétricos à foliação milonítica (Fig.10C).

A amostra MG-171, do domínio sudoeste (protomilonito granítico), apresenta distribuição dos máximos dos pólos de eixos-c de quartzo ao longo de duas guirlandas de círculos mínimos em torno de X (Fig. 10B). Este caso é compatível com deformação coaxial em campo constritivo (Schmidt \& Casey 1986), sugerindo deslizamento prismático, indicando campo de mais alta temperatura ou menores taxas de deformação (Tullis 1977).

A análise das petrotramas mostra gradação de um domínio no qual predomina o achatamento (domínio nordeste) para um domínio onde predomina a constrição (domínio sudeste), passando pelo domínio central, em que obtém-se um padrão das petrotramas pouco caracterizado, podendo representar transição entre os dois domínios.

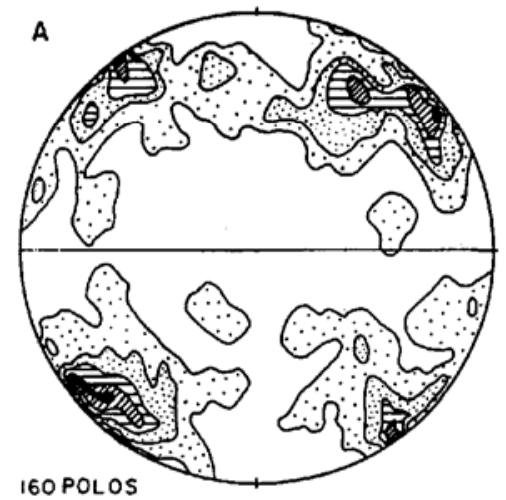

160 POLOS

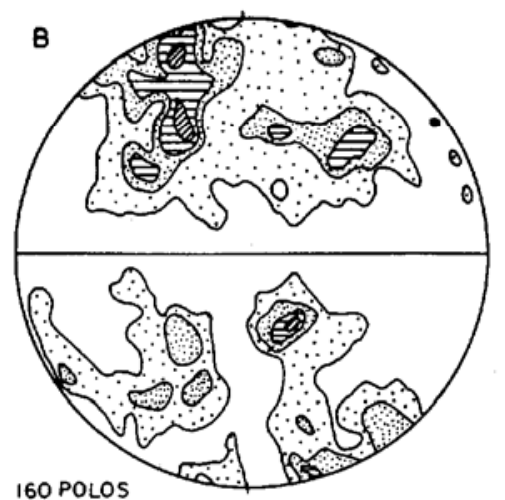

160 POLOS
160 POLOS

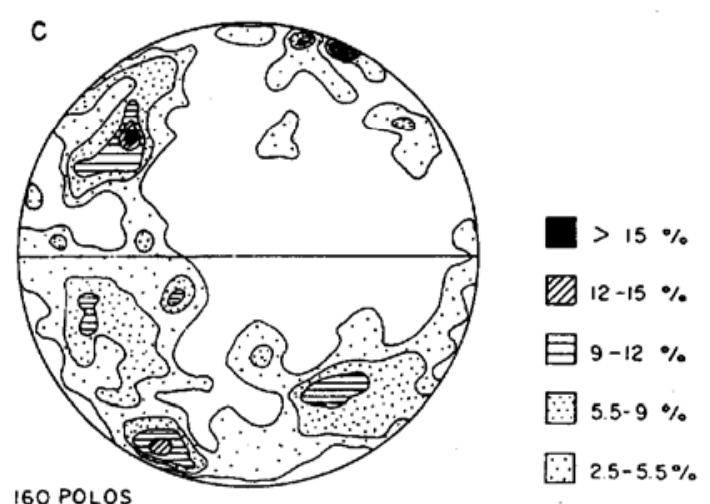

Figura 10 - Estereogramas de eixo-c de quartzo, obtidos em amostras da ZCMG. A. Milonito granítico (MG-186b); B. Protomilonito granítico (MG-171b); e C. Milonito granítico (MG-198)

Figure 10 - Quartz c-axis fabrics on mylonitic rocks from the MGSZ 
ANÁliSE DA DEFORMAÇÃO Procurando determinar o campo de orientações do eixo de encurtamento máximo (Z), a orientação das elipses de deformação e conseqüente sentido de movimento da $\mathrm{ZCMG}$, procedeu-se a análise de centros de porfiroclastos em amostras orientadas (método de Fry 1979), tal como apresentado em Ramsay \& Hubber (1983).

Diversos autores advertem sobre o uso deste método em isolado, pois uma das premissas do mesmo admite que o centro de cada cristal sempre permaneceu como o centro, isto é, antes e após a deformação. Tal premissa não pode ser aceita como geral. Entretanto, isso pode ser minimizado quando se utiliza em conjunto com outras informações e para a determinação qualitativa da orientação espacial dos eixos de deformação principais.

Outra questão importante relaciona-se ao tipo da rocha para qual o método é utilizado. Este método é inadequado para rochas muito xistosas, nas quais a matriz micácea concentra a deformação. Nesses casos, a relação entre a Rf (razão entre os eixos X e Z da elipse de deformação) e o ângulo entre o eixo $X$ e a horizontal de referência, torna-se muito irregular, resultando em elipse não-representativa.

Foram realizadas seis análises em rochas miloníticas e protomiloníticas, cujos dados encontram-se plotados na tabela 1. Na análise pontual (relação entre o eixo-Z e a direção da foliação milonítica no afloramento), obteve-se em três amostras indicações de movimentação lateral dextral, onde o eixo X da deformação finita forma um ângulo entre $58^{\circ} \mathrm{e}$ $37^{\circ}$, com a direção da foliação milonítica. Duas amostras forneceram relações compatíveis com deformação coaxial, tendendo a não-coaxial dextral (ângulo de $6^{\circ}$ entre o eixo X e a direção da foliação milonítica). Uma relação de movimento sinistrai foi obtida, sendo o ângulo eixo $\mathrm{X} /$ foliação milonítica de $22^{\circ}$.

A observação, em mapa, da relação entre a orientação das elipses de deformação e os limites da faixa milonítica da ZCMG, permitem caracterizar movimentação predominantemente dextral, com uma componente coaxial importante.

A extrapolação dos resultados da análise pontual, para uma análise geral, foi em decorrência da coerência obtida entre as orientações das elipses de deformação determinadas. E importante ressaltar, no entanto, que nem sempre existe concordância entre as orientações do eixo X (direção de extensão principal) de elipses e as lineações de estiramento medidas no afloramento. Estas possuem caimentos preferenciais para S40W (subprdinadamente para N50E), enquanto apenas metade das orientações obtidas para o eixo $\mathrm{X}$ apresentam direção N45E. As demais exibem valores fortemente oblíquos (S20E e N07W) em relação as direções das lineações de estiramento (Tab. 1).

$\mathrm{O}$ valor da elipsidade, ou seja, a razão entre os eixos $\mathrm{X}$ e $\mathrm{Z}$ da elipse de deformação (Tab. 1), varia entre 1,7 e 1,9, para as rochas situadas na porção central da faixa milonítica. A amostra situada próxima à parede da faixa milonítica apresenta elipsidade maior $(2,12)$.

IMPLICAÇÕES REGIONAIS Conforme Hallinan et al. (1993), em mapa de anomalias Bouger do Sul do Brasil e Uruguai, a feição mais importante e contínua observada é uma anomalia negativa que se estende desde Santa Catarina até o Uruguai, paralelamente às Zonas de Cisalhamento Major Gercino, em Santa Catarina, Dorsal de Canguçu, no Rio Grande do Sul, e Sierra Ballena, no Uruguai. Esta feição pode representar, pelo modelo gravimétrico assumido, estruturas de expressão litosférica (conforme também Basei 1990 e Tommasi et al. 1992). Essa anomalia negativa, apesar de paralela à ZCMG, está deslocada para leste, situando-se sobre o complexo granito-migmatítico do Cinturão Dom Feliciano.

Entretanto, devem ser enfatizadas diferenças importantes entre estas zonas de cisalhamento. Em SC, a ZCMG separa duas áreas geologicamente distintas: os terrenos compostos de rochas supracrustais do Grupo Brusque do complexo granito-migmatítico, com diferenças não só litológicas, mas também geoquímicas e geocronológicas marcantes (Basei 1985).

A faixa milonítica principal dessa zona de cisalhamento, na área estudada, exibe preferencialmente movimentação lateral dextral e oblíqua, em regime compressivo e com soerguimento do complexo granito-migmatítico. Movimentações dextrais oblíquas e de caráter distensivo ocorrem no setor sudoeste da área e, em ambos os casos, a deformação tende ao cisalhamento puro.

No Rio Grande do Sul, a Zona de Cisalhamento Dorsal do Canguçu (ZCDC), preferencialmente sinistrai, faz em parte o limite entre as rochas metassedimentares e o domínio dos granitóides. Descarta-se o caráter de sutura entre dois blocos crustais de origem e natureza diferentes (UFRGS 1993 in Fernandes et al. 1990, Mesquita \& Gomes 1991).

No Uruguai, a Zona de Cisalhamento Sierra Ballena (ZCSB) marca somente em parte o contato frontal dos granitóides com os metassedimentos e apresenta movimento sinistrai (Bossi \& Campal 1992).

Em Santa Catarina, grande parte dos granitóides que ocorrem regionalmente a sul da ZCMG são pré-cinemáticos

Tabela 1 - Relações entre os dados obtidos pelo Método de Fry e os dados de campo (lineação de estiramento mineral, Lm, e foliação milonítica, Sm). Também estão relacionadas as movimentações obtidas por meio da análise pontual e geral Table 1 - Comparison between the data obtained from the Fry analysis and the field data (stretch mineral lineation and mylonitic foliation)

\begin{tabular}{|c|c|c|c|c|c|c|c|}
\hline \multirow{2}{*}{ Amostra } & \multirow{2}{*}{$\begin{array}{l}\text { Foliação de } \\
\text { milonítica }\end{array}$} & \multirow{2}{*}{$\begin{array}{l}\text { Lineação de } \\
\text { estiramento }\end{array}$} & \multirow{2}{*}{\multicolumn{2}{|c|}{$\begin{array}{c}\text { Eixos do elipsóide } \\
\text { de deformação } \\
\text { Eixo } \mathrm{X} \quad \text { Eixo Z }\end{array}$}} & \multirow{2}{*}{$\begin{array}{l}\text { Elipsidade } \\
\text { (Rf) }\end{array}$} & \multicolumn{2}{|c|}{$\begin{array}{l}\text { Sentido de } \\
\text { movimento }\end{array}$} \\
\hline & & & & & & $\begin{array}{l}\text { Análise } \\
\text { pontual }\end{array}$ & $\begin{array}{c}\text { Análise } \\
\text { Geral }\end{array}$ \\
\hline MG-32 & N55E/64SE & $\mathrm{S} 40 \mathrm{~W} / 34$ & N07W/12 & S80W/27 & 1.77 & Dextral & Dextral \\
\hline MG-38 & $\mathrm{N} 35 \mathrm{E} / 67 \mathrm{NW}$ & S65W/67 & $\mathrm{S} 20 \mathrm{E} / 46$ & $\mathrm{~W} / 23$ & 1.92 & Dextral & Dextral \\
\hline MG-114 & $\mathrm{N} 45 \mathrm{E} / 60 \mathrm{NW}$ & S50W/09 & S40W/02 & $S 45 E / 33$ & 1.82 & (Cis. Puro) & (Cis. Puro) \\
\hline MG-171 & N55E/70SE & S30W/40 & N57E/42 & N40W/05 & 1.60 & Sinistral & (Cis. Puro) \\
\hline MG-186 & N65E/69SE & N60E/66 & $\mathrm{S} 20 \mathrm{E} / 45$ & $\mathrm{~N} 45 \mathrm{~W} / 42$ & 2.12 & Dextral & Dextral \\
\hline MG-198 & $\mathrm{N} 40 \mathrm{E} / 77 \mathrm{SE}$ & $\mathrm{N} 50 \mathrm{E} / 33$ & N57E/22 & $\mathrm{N} 47 \mathrm{~W} / 32$ & 1.73 & Dextral & (Cis. Puro) \\
\hline
\end{tabular}


a esta estrutura e foram justapostos aos metassedimentos do Grupo Brusque através desta zona de cisalhamento.

Pela orientação do esforço principal deduzida para a ZCMG, por meio da análise da deformação, é compatível com a movimentação dextral na ZCMG a movimentação sinistrai na ZCSB, no mesmo episódio, já que esta última possui direção aproximada N15E. Mas, para a $\mathrm{ZCDC}$, que possui direção semelhante à da $\mathrm{ZCMG}$, torna-se incompatível movimentação sinistrai no mesmo período, com a direção do esforço principal deduzida neste trabalho. De fato, torna-se necessário o refinamento destas determinações a respeito da direção preferencial de compressão, bem como, datações das rochas miloníticas geradas nessas zonas de cisalhamento para elucidar este problema.

CONCLUSÕES A ZCMG teve evolução cinemática complexa, fato este confirmado pelas estruturas mesoscópicas, pelas análises obtidas pelo método de Fry e pelos eixos-c de quartzo.

Se a movimentação foi preferencialmente dextral, a orientação da faixa milonítica estudada em relação ao campo de tensores permitiu que importante componente da deformação fosse por cisalhamento puro, acarretando, em inflexões locais, movimentações sinistrais.

Uma disposição em flor positiva para a ZCMG é sugerida pelas foliações miloníticas limítrofes da zona de cisalhamento. A persistência local de domínios transpressivos e a componente coaxial da deformação podem ter sido responsáveis pelas dobras cilíndricas desta foliação nas porções de fraco mergulho da estrutura em flor (Figs. 3 e 6).
A obliqüidade da lineação de estiramento sugere o soerguimento do domínio granito-migmatítico em relação ao domínio das rochas supracrustais.

$\mathrm{Na}$ análise estrutural realizada, observa-se que a componente coaxial é evidenciada por petrotramas de concentrações simétricas e elipses de deformação com eixo $\mathrm{Z}$ a $90^{\circ}$ da foliação milonítica. $O$ cisalhamento puro pode também ter predominado anteriormente a um cisalhamento simples dextral, fato este sugerido pelos diagrama de petrotramas de eixo-c (Fig. 10A).

A existência de porfiroclastos simétricos, por vezes com sombras de pressão simétricas, e a presença de envoltórias de mica em granadas (mica cap) também sugerem uma componente da deformação por cisalhamento puro.

A orientação cristalográfica desenvolveu-se sob temperaturas relativamente baixas, indicada pelo metamorfismo que pode ter atingido a zona da almandina da fácies xisto verde, bem como pelos petrotramas. Apesar da baixa temperatura, esta orientação originou-se sob condições de alta taxa de deformação, evidenciada pela presença de minerais deformados e estirados e pela geração de rochas miloníticas e ultramiloníticas, onde há total paralelização das superfícies.

Movimentações rúpteis tardias são sugeridas pela presença de rochas granitóides com feições cataclásticas e pela presença, em seções delgadas, de minerais com fraturas transgranulares.

Agradecimentos A primeira autora agradece à FAPESP pela concessão da Bolsa de Mestrado, Processo n ${ }^{\circ}$ 92/37293. Os Profs. Miguel A.S. Basei e Mário C. Campos Neto agradecem ao CNPq pelas Bolsas de Pesquisador, que são portadores.

\section{REFERÊNCIAS BIBLIOGRÁFICAS}

BASEI, M.A.S. 1985.0 Cinturão Dom Feliciano em Santa Catarina. São Paulo. 190 p. (Tese de Doutoramento, IG-USP).

BASEI, M.A.S. \& TEIXEIRA, W. 1987. Geocronologia dos Terrenos PréCambrianos a Eopaleozóicos de Santa Catarina. Texto Explicativo para o Mapa Geológico do Estado de Santa Catarina - 1:500.000. In: SILVA, L.A. \& BERTOLUZZI, C.A. eds. Florianópolis, DNPMCPRM. p. 91-130. (Secção Geologia, Série Mapas e Cartas de Sínte-

se 3).

EI, M.A.S. 1990. The Major Gercino - Dorsal do Canguçu Shear Zone. 15* v In: COLLOQUIUM ON AFRICAN GEOLOGY, 15. Nancy, France, 1990. Abstracts... Nancy, France, 166 p.

BASEI, M.A.S.; SIGA JÚNIOR, O.; MACHIAVELLI, A.; MANCINI, F. Evolução tectônica dos terrenos entre os Cinturões Ribeira e Dom Feliciano (PR - SC). Rev. Bras. Geoc., 22(2):216-221.

BITENCOURT, M. F.; HACKSPACHER, P.C.; STOLL, L.V. 1989. A Zona de Cisalhamento Major Gercino - Santa Catarina. In: SIMP. NAC. EST. TECT, 2. Fortaleza, 1989. Fortaleza, SBG. Boi. 11, p. 214-215.

BOSSI, J. \& CAMPAL, N. 1992. Magmatismo y tectônica transcurrente durante ei Paleozoico Inferior en Uruguay. In: GUTIÉRREZ-MARCO, J.C.; SAAVEDRA, J.; RÁBANO, I. eds. Paleozoico Inferior de Ibero-América. Extremadura, Universidad de Extremadura. p. 343-356.

CALDASSO, A.L.S.; CAMAZZOTO, E.; RANGRAB, G.E.; SILVA, M.A.S. 1988. Os Granitóides Valsungana, Guabiruba e Faxinai no contexto dos metamorfltos do Complexo Brusque, SC. In: CONGR. BRAS. GEOL., 35. Belém, 1988. Anais... Belém, SBG. v. 3, p. 1104-1116.

DELUANGELO, L.N. \& TULLIS, J. 1989. Fabric development in experimentally sheared quartzites. Tectonophysics, 169:1-21.

FERNANDES, L.A.D.; TOMMASI, A.; PORCHER, C.C. 1990. Esboço estrutural de parte do Batólito Pelotas - região de Quitéria-Capivarita. Acta Geol. Leopold., 13:117-138.

FRAGOSO-CESAR, A.R.S. 1980.0 Cráton do Rio de La Plata e o Cinturão Dom Feliciano no Escudo Uruguaio-Sul-Riograndense. In: CONGR. BRÁS. GEOL., 31. Camboriú, 1980.Anais... Camboriú, SBG. v. 5, p. 2879-2892.

HALLINAN, S.E.; SHUKOWSKY, W.; MANTOVANI, M.S.M. 1993. Estruturação do embasamento Pré-Cambrico da região sul do Brasil e
Uruguai: novos modelos resultantes de densificação gravimétrica./fev. Brás. Geoc., 23(3):201-214.

HASUI, Y; CARNEIRO, C.D.R.; COIMBRA, A.M. 1975. The Ribeira Folded Belt. Rev. Bras. Geoc., 5(4):257-266.

HOBBS, B.E.; MEANS, W.D.; WILLIAMS, P.P. 1976. An Outline of Structural Geology. New York, Wiley \& Sons. 571 p.

KAUL, P.F.T. 1976. Projeto Brusque - Serra do Tabuleiro. Porto Alegre, DNPM/CPRM. p. 6. (Relatório Final). (Inédito).

LEE, J.; MILLER, E.L.; SUTTER, J.F. 1987. Ductile strain and Metamorphism in a Extensional Tectonic Setting: A case study from the northern Snake Range, Nevada, USA. In: COWARD, M.P.; DEWEY, J.F.; HANCOCK. P.L. eds. Continental Extensional Tectonics, Geological Society, p. 267-298. (Special Publication 28).

LISTER, G.S. 1977. Discussion: crossed-girdle c-axis fabrics in quartzites plastically deformed by plane strain and progressive simple shear. Tectonophysics, 39(1-3):51-54.

LISTER, G.S. \& SNOKE, A.W. 1984. S-C Mylonites. J. Struct. Geol., 6(6):617-638

MANTOVANI, M.S.M.; SHUKOWSKY, W.; BASEI, M.A.S.; VASCONCELLOS, A.C.B.C. 1989. Modelo gravimétrico das principais descontinuidades crustais nos Terrenos Pré-Cambrianos dos Estados do Paraná e de Santa Catarina. Rev. Bras. Geoc., 19(3):367-374.

MANTOVANI, M.S.M.; VASCONCELLOS, A.C.B.C.; SHUKOWSKY, W; MILANI, E.J.; BASEI, M.A.S.; HURTER, S.J.; FREITAS, S.R.C. 1991. Brusque Transect from Atlantic Coast to Bolivian Border, Southern Brazil. Washington, American Geophysical Union. 20 p. (Global Geoscience Transect 4).

MESQUITA, M.J.M. \& GOMES, M.E.B. 1991. Correlação estrutural e geoqufmica de granitóides sin-cinemáticos à zona de cisalhamento Dorsal de Canguçu, RS. In: CONGR. BRAS. GEOQ., 3. São Paulo, 1991. Resumos... São Paulo, SBGq. v. 1, p. 286-288.

PASSCHIER, C.W. \& SIMPSON, C. 1986. Porphyroclast systems as kinematic indicators./. Struct. Geol., 8(8):831-843.

RAMSAY, J.G. \& HUBBER, M.1.1983. Practical strain measurement. In: The Techniques of Modern Structural Geology. London, Academic Press, p. 107-125.

SCHMIDT, S.M. \& CASEY, M. 1986. Complete fabric analysis of some commonly observed quartz c-axis patterns. In: HOBBS, B.E. \& 
HEARD, H.C. eds. Mineral and Rock Deformation: Laboratories Studies, p. 263-286. (Geophysical Monograph 36).

SCHULZ JUNIOR, A.; ALBUQUERQUE, L.F.F.; GIFFONI, L.E. 1969. Geologia da Quadricula Rio do Sul, SM. Porto Alegre, DNPM. p. 109. (Inédito).

SILVA, L.C.; OLIVEIRA, J.M.P.; AUMOND, J.J.; LOPES, R.M.M.; EIPPER, J.; FERRO, G. 1985. Caracterização petrográfica da seqüência (meta)vulcano-sedimentar Rio do Oliveira. In: SIMP. SUL-BRAS. GEOL., 2. Florianópolis, 1985. Anais... Florianópolis, SBG. v. 1, p. 11-23.

SIMPSON, C. 1980. Oblique girdle orientation patterns of quartz C-axes from a shear zone in the basement core of the Maggia Nappe Ticino, Switzerland. J. Struct. Geol., 92(1/2):243-247.

SIMPSON, C. \& SCHMID, S.M. 1983. An evaluation of criteria to deduce the sense of movement in sheared rocks. J. Struct. Geol., 94:12811288.

TOMMASI, A.; FERNANDES, L.A.D.; PORCHER, C.C.; VAUCHEZ, A. 1992. Movimentação paralela e transversal aos limites de placas durante uma colisão continental - exemplo do Cinturão Dom Feliciano,
RS. In: CONGR. BRÁS. GEOL., 37. São Paulo, 1992. Boletim de Resumos Expandidos... São Paulo, SBG. v. 1, p. 286-287.

TOMMASI, A.; VAUCHEZ, A.; FERNANDES, L.A.D.; PORCHER, C.C. 1994. Magma-assisted strain localization in an orogen-parallel transcurrent shear zone of southern Brazil. Tectonics, 13(2):421-437. TRAININI, D.R.; DIAS, A.A.; KREBS, A.S.J.; SOUZA, E.C.; CAPELETTI, L; TONIOLO, J.A.; SILVA, L.C.; SILVA, M.A.S 1978. Projeto Vidal Ramos - Biguaçu. Porto Alegre, DNPM/CPRM. 303 p. (Inédito)

TULLIS, J. 1977. Prefered orientation of quartz produced by slip during plane strain. Tectonophysics, 39(1-3):87-102.

TURNER, F.J. \& WEISS, L.E. 1963. Structural Analysis of Metamorphic Tectonites. New York, McGraw-Hill. 545 p.

MANUSCRITO A787

Recebido em 9 de setembro de 1993

Revisão do autor em 20 de julho de 1994

Revisão aceita em 14 de março de 1995 